\title{
Globalization and Study Abroad: An Illusion of Paradox
}

\author{
R i c h a r d F a I k \\ Princeton University \\ Na ncy A. K a n a c h \\ Princeton University
}

\section{Points of Departure}

Economic globalization, together with the communications revolution, is perceived by some to be responsible for a homogenizing effect on societies around the world. A consumerist ethos disseminated by huge advertising budgets and the ease and speed of communication lend a certain plausibility to such perceptions. Some argue that if such trends persist, the growing familiarity of world regions with one another will gradually yield to a kind of sameness. If such is the case, the pedagogical benefits of travel and a foreign perspective will presumably diminish, if not altogether disappear. If cyberspace becomes the milieu of choice in the years ahead, then it would appear to matter little, if at all, where to situate coordinates of time and space.

As we reflect upon the benefits of study abroad we should also bear in mind the special nature of such programs in settings outside the developed world. In the United States and other comparably-situated countries, the opportunity to study abroad enhances an already sound educational program. This is different from the conception of study abroad that leads developing countries to allocate scarce resources to fund foreign scholarships for their young people. The motivations in these cases are primarily vocational training geared around the skill requirements of economic development in a globalizing world, or servicing the international outlook of privileged Third World elites. Such journeys overseas are conceived to be investments in the future, but they are not without their risks. Among the uncertainties associated with this very different orientation to "study abroad" are such issues as "brain drain" and political back- 
lash, which are beyond the scope of our inquiry. But we should not ignore the very different motivations that foreign students may have in choosing to study here, while we consider the benefits (and risks) of having American students participate in programs of comparatively short-term study abroad.

The context of globalization generates a special set of issues that illustrate both types of study abroad programs. It should be appreciated that part of the world conceives of globalization as providing a levelingup opportunity to overcome poverty and backwardness at breakneck speed. Another part, however, views globalization with great suspicion, as either a dangerous embrace of decadent Westernized values and lifestyle, or more dramatically, as an American project for world domination. Many students of international politics believe that these anxieties and hostilities have contributed to extremist revivals of traditional culture in various parts of the Islamic world. Such revivals have most notably been expressed in the form of a religious resurgence, although the particular shape and content of this resurgence varies greatly from country to country and over time. The more extreme expressions of this pattern have included an indictment of the West and the United States, and have exhibited a generalized suspicion of modernity. Such developments in each instance reflect a complex interplay of attitudes, but invariably a series of negative reactions to globalization is a significant part of the story.

Iran provides a stark example that illustrates both sides of this dynamic. Iran's shift away from a Western-oriented authoritarian government bent on modernization under the Shah to a passionately anti-United States regime professing above all an Islamic identity resulted initially in a drastic double-reversal in the country's attitude toward study abroad. First of all, a significant part of the anti-Shah revolutionary zeal came from students sent to Europe and North America to gain the skills and training needed to facilitate rapid modernization at home, but who became highly politicized while outside their country. Secondly, the Iranian Revolution resulted in the immediate termination of this pattern of subsidized education abroad for young Iranians, as the project of modernization was viewed with skepticism and was certainly no longer regarded as a priority. A new emphasis was placed upon education of Iranians at home under a strict religious and cultural tutelage. Thirdly, foreign students, unless Islamic, were no longer welcome in Iran. Although this early pat- 
tern of anti-secular backlash in Iran represented an extreme, it does highlight the different perceptions of study abroad when viewed in an antiglobalization context from the foreign end of the telescope.

That is, globalization, broadly conceived, seems to have set in motion these contradictory patterns of action and reaction that both erode, if not altogether undermine, the case for study abroad. On the one side, the juggernaut of globalization makes it seem as if going abroad generates only the most minimal insight as the cumulative drift of development is toward a high-tech, inter-societal convergence. On the other side, the traditionalist backlash generates an atmosphere of hostility and antagonism that explicitly repudiates the major rationale for study abroad, and views the experience of either incoming or outgoing students as being both corrupting and as a sly form of cultural intervention that contains a neo-colonial subtext. In light of such considerations, it seems desirable to reformulate the goals and benefits of study abroad in a manner that is sensitive to the altered conditions brought on by globalization, while at the same time appreciating the continuities that have long made foreign travel and study a precious educational benefit.

\section{A Favorable Climate of Opinion}

There is no doubt that where an atmosphere of hostility toward the United States exists, it restricts, if not altogether precludes, the mutually beneficial operation of study abroad programs. In these circumstances, prudence, as well as calculations of educational benefit, will likely induce a suspension of such programs, at least while the tension persists. But happily, the climate of opinion on matters of such interaction changes rapidly. In fact, with the recent emphasis by non-Western governments associated with either a religious or cultural identity ("Asian values") on "a dialogue of civilizations" rather than "a clash of civilizations," the groundwork for a renewed endorsement of overseas educational exchange programs may have already been brought into being. To the extent that such study abroad programs can be safely arranged and carried on in a nonrepressive atmosphere of free inquiry, they can offer learning experiences of unprecedented depth and potentially contribute to a general atmosphere of inter-civilization tolerance, even appreciation, whose benefits extend well beyond the classroom. 
It seems justifiable to view our Iranian example in a more positive light at this point. Despite the ebb and flow of contending tendencies within Iran, leading to advances and setbacks for moderating forces, the intellectual atmosphere in the country, including its universities and book stores, is lively. This atmosphere of debate and reflection would make the experience of study for American students in Iran valuable and potentially transformative, creating an awareness of the strengths and weaknesses of political Islam in ferment. Similarly, Iranian students coming to the United States or elsewhere in the West could help make the commitment to dialogue a reality that could possibly alleviate the materialism of globalization in its mainly American format, and allow the affirmation of tradition to benefit fully from participation in a more integrated world economy, including the sort of access to science and technology that would allow poorer countries to serve better the needs of their citizens.

Educational exchange in politically-charged environments provides special insights and opportunities for students. The recent proliferation of study abroad programs in Cuba is another instructive example. The growing number of educational programs in Cuba will undoubtedly encourage an exchange of views and an unprecedented opportunity for Cubans and Americans alike to confront and alter preconceived notions of each other's identity and values. The effect of this interaction is not yet known. Perhaps it could contribute to a climate of opinion that is favorable to lifting the embargo that has for so long obstructed American contacts with Cuba. This would allow for a wider range of interactions and a more nuanced understanding of the attitudes, including the misunderstandings, that exist in both countries, but more negative effects cannot be ruled out. It is quite possible that competing propaganda efforts of the two countries might reinforce distrust and hostility in conditions of increasing interaction, and lead influential groups in Cuba to become disillusioned with such attempts at improving relations between our two countries on the basis of a bottom-up approach resting on student exchange. As suggested earlier, study abroad does not provide guarantees, but it does open windows, and that seems beneficial despite attendant risks.

At this first level of approximation, then, the tensions unleashed in part by globalization should not be viewed as enduring obstacles to study abroad programs, but rather as temporary impediments that can, with imagination and patience, under most conditions, yield unusually valu- 
able learning opportunities. At a second level, the extent to which globalization is thought to generate sameness, the case for study abroad would seem to grow stronger. For one thing, on-the-ground experience would shatter the myth of homogenization that often overstates the impact of popular culture and consumerism on overall societal identity. In so doing, it would disclose for students the extent to which vast and vivid cultural differences persist, and may actually be intensifying as a counter to globalization. Moreover, they would see that these differences are generally worth celebrating and are not occasions for lament. Even though the metaphor of "a global village" speaks to some dimensions of our current situation, it needs to be combined with the complementary image of diverse neighborhoods. The condition of growing interaction makes it more important than ever that we Americans understand how our influence and global role is understood by others, both as models to be imitated and as forces to be feared. In a globalizing world of Disney icons and corporate logos, globally disseminated by music and TV, but mainly deriving from American popular culture, the reality of human contact is of growing significance if dangerous stereotypes on all sides are to be avoided, and the struggle for genuine understanding is to make progress.

\section{An Assessment}

These generalizations apply to West/non-West or North/South relations overall, but with special force to the relationship between the United States and the rest of the world. For many peoples in the world, including those in Europe, globalization is often naively regarded as an American project to achieve outright global domination. Globalization is not regarded as a neutral consequence of the application of neo-liberal economic principles seeking efficiency in the allocation of resources and growth, but is a fusion of such an economic outlook with an unprecedented concentration of military power and diplomatic influence. It is important for young Americans to understand this outlook and to help in the dual process of evaluating and absorbing its insights, while at the same time working to correct its distortions and diminish its overbearing tendencies. Similarly, cultural interaction will encourage diverse understandings of globalization, including varying appraisals of its advantages and disadvantages in different areas of study. In turn, this will enable the 
formation of more sophisticated attitudes in the United States, not only in the economic and political spheres, but perhaps most prominently in cultural studies. Students who have had well-integrated and rewarding experiences abroad do see the world differently upon their return, and carry these insights and memories with them throughout their lives. Their subsequent studies and careers are often marked by what they have learned through their international experience. At a time when America seems so inwardly preoccupied and lacking the sort of global challenge associated with the Cold War period, this infusion of internationalist concerns on the part of our young citizens seems more indispensable than ever.

\section{Contemporary Study Abroad and GIobalization}

Study abroad is, of course, in no way the functional equivalent of the nineteenth-century Grand Tour. This earlier mode of "study abroad" romanticized the genial meeting of two cultures by way of leisurely and luxurious travel abroad by youthful members of privileged classes who tended to seek out and interact with their wealthy counterparts in exotic foreign settings. With the growing interdependence of regions and nations, there is much more at stake, and the whole venture of study abroad has happily lost touch with this aristocratic heritage. Because of the political, economic, and cultural role of the U.S. in countries and societies around the globe, U.S. interests are at once more powerful and more vulnerable. U.S. students abroad learn firsthand how it feels to be a representative of the most powerful nation on earth and at the same time to experience that power from the point of view of those on the receiving end.

An American student's experience in France is a good example. While there are periodically loud outbursts of anti-Americanism, the influence of the U.S. is also often welcomed, even cheered in France, which carries on an intense love affair with American popular culture, especially our music and film. The contradictory attitudes toward the U.S., sometimes unstated, often even unrecognized, inform the tone of much of the public debate. The U.S. is not simply dismissed or much less ignored, but rather treated as an insidious and very present dimension of French life. Because there is no firm conclusion about how to view the U.S., the state of mind in French society is both unstable and ambivalent, 
easily swayed by passing events and even offhand comments. Especially since the end of the Cold War and the consequent reduction of anti-U.S. ideological attitudes, the confusing realities encountered in France are replicated to varying degrees in other countries that are trying to come to grips with the different aspects of globalization.

Globalization is also bound up with the Internet and the Information Age. To some extent, the unequal access to these technological innovations that dramatically alter our relation to information (if not knowledge and wisdom) and to commerce is creating "a digital divide." The gaps between those who have ready access to computers and those who do not is defining the realities of a globalizing world. To comprehend this fundamental circumstance, it is again helpful to experience these developments firsthand, and from a non-American perspective. Some of this experience suggests that the divide is not nearly as much along geographical lines as was the earlier relationship between the metropoles of Europe and the colonized world during the formative era of the Industrial Age. Digitally-sophisticated places like Bangalore or Penang, let alone Singapore or Taipei, suggest that the digital divide does not neatly separate North and South or West and East. In this sense, there are fascinating mixtures of traditional, modern, and postmodern culture that await those who participate in study abroad programs. Such possibilities exist both in long-recognized Western centers of learning and in a series of flourishing global cities. Many of these newly ascendant urban settings embody the complex impacts on the generation of wealth and influence associated with globalization in forms that can be quickly comprehended if experienced, but remain an abstraction if studied from afar.

Globalization is also giving rise to contradictory trends regarding multiculturalism and overall human solidarity. On the one side, the rise of identity politics is producing less coherent national societies, especially as abetted by inter-civilizational migratory patterns. Even the melting-pot metaphor, long relied upon to establish the reality of a unified national identity able to transform disparate ethnic identities of immigrant groups within a generation or so, has been questioned here in America where it originated. Increasingly, the talk is of "multiculturalism," of a drawing together of people into their respective ethnic communities - an often proud refusal to melt - that leads to an overall identity that is permanently diverse in a manner that fundamentally denies 
the pretension of a world of "nation-states."

Moving in a quite opposite direction, there is a growing realization that democracy and human rights have an increasingly global reach that provides both a stabilizing and humanizing commonality essential for travel, trade, and problem-solving over long intervals of time. To relate to these patterns outside the familiar setting of one's own country is of evergreater relevance to a comprehension of change in the world as a whole. Such a perspective and experience from without has the prospect of contributing to a more knowledgeable and creative type of citizenship within and vice versa. And it may lead to a more complex multi-layered notion of citizenship that extends to region and world, such as we see emerging on the European landscape. More and more people seem to affirm multiple loyalties, and do not exhaust their sense of political identity through their relationship to a particular state.

The first groups of university students to study in post-apartheid South Africa in the mid-nineties were pioneers of sorts. The students felt privileged to witness a country in the throes of reinventing itself, to see black South Africans excitedly waiting in lines to cast a vote for President after having been denied all forms of meaningful participation in political life for decades. Many visiting students were caught up in the optimism of the first years of Nelson Mandela's presidency, and a number who had studied abroad in South Africa returned there after graduation to continue working on issues ranging from low-cost housing to developing training programs to help young South Africans learn sound techniques for public administration. This was not the missionary work of an earlier era that had characterized much of the foreign intervention in Africa, but the actions of young Americans who had developed a human solidarity with the people of South Africa and also understood that their own world would be better off with an economically successful and democratically stable nation at the southern end of the African continent. As well, many of these students realized that they were witnessing a sort of secular miracle in South Africa, the dismantling of a racist structure, without violence and with a minimum of rancor. American students had much to learn generally from viewing this inspirational model of political action, and through their participation were unconsciously implementing an alternative globalization to that being so vigorously pushed by market forces. 
Other important changes are taking place in the world that are associated with globalization, although not exclusively or directly. Perhaps the most significant of these is the multi-dimensional experiment unfolding in Europe with respect to the growth and development of regional governance. In some sense, study abroad by Europeans within Europe - first, the ERASMUS and now the SOCRATES Program-is itself playing an important role in the creation of a regional identity. The Europeans knew that moving students across borders, forcing national institutions to credit academic work completed at institutions in other countries, would promote the transnational and regional paradigm that they hoped to embody in increasingly integrated forms of regional governance. Americans studying abroad in Europe will find themselves inevitably immersed in sharp and fascinating debates about the contours and goals of Europeanization, about whether regionalism is a constructive response to the pressures and opportunities of globalization, and how such a course will affect national identity, as well as the role, character, and future of the sovereign state and the situation of ethnic minorities. At the same time, other regions are both watching Europe and initiating regional experiments of their own. It is not only a matter of grasping the meaning of regionalism, but experiencing the degree to which the classical idea of the sovereign territorial state is coming under many pressures from globalization and how various states and their corresponding dominant cultures are responding to the lure of different regionalisms. Exposure to these social, political, and economic developments gives a special historical relevance to study abroad programs.

Europe is still the most popular destination for U.S. students studying abroad. Now, however, when students study in France or England, for example, they typically are part of a diverse international student population from countries all over the globe and with a wide mixture of races, religions, and class backgrounds. This does not mean that the culture that they find themselves in is masked by the multinational student body and hidden from view. It does confirm that an increasing number of students are now able to cross borders and situate themselves in a cosmopolitan setting located in a foreign country. It follows that U.S. students abroad, carrying their symbolic baggage of citizenship of a country widely regarded with both awe and hostility, but rarely, if ever, indifference, will encounter a wide range of attitudes, including misapprehensions and envious derision. It is likely, however, that many American citizens in the future will 
not find this fact disorienting or disturbing because they will have developed a sufficient sense of multiple loyalty associated with regional affinities and human solidarities to avoid reacting with defensiveness. Such a broadening of outlook by Americans is fully consistent with a continuing allegiance to their own country, but would ideally give rise to a greater commitment to listening to what others have to say, and a greater effort to challenge those aspects of their own national identity that are objectionable to outsiders.

Politically active women studying abroad often find themselves relating to gender issues in their host countries. They come to feel a solidarity with their local counterparts and observe and sometimes participate in their struggles, which range from domestic violence, human rights violations, economic sustainability to reproductive rights and other issues tied to gender inequality. Whether collecting statistics for political action, volunteering in women's shelters, or helping to identify and correct gender bias in areas of education, law, and the economy, many women who study abroad learn much from their interaction with those who are dealing with these issues under differing national circumstances. They are afforded an important perspective on the cultural constructs that support gender inequities.

\section{Confronting Challenges}

The challenges that confront the world and for which global cooperation is critical, in areas such as the environment, health, and security, give rise both to a growing sense that "human identity" is crucial and an opposite sense of fragmentation that deters collaborative responses. On the one side are concerns such as genocide or global warming, and on the other, a seemingly opposite sense that matters of ethnic, religious, cultural, and gender identity are more important than ever to avoid being swallowed by the monster of globalization.

To approach this seemingly common agenda from the perspective of study abroad can only deepen and enliven a young person's search for identity and meaning in this era of globalization. While the world is shrinking, we cannot shrink from it. National policies in other countries have recognized the critical role that study abroad plays in the education and training of their citizens and, increasingly, national or regional policies 
call for greater access to international education and experience. The progress that Europe has made in training multilingual, culturally and politically knowledgeable men and women owes much to the bold steps charted by the student mobility schemes of the last decade.

International education has had a more difficult time finding its place on the national agenda in the U.S. Last year, the National Association of International Educators (NAFSA) proposed that the U.S. implement an international education policy that would support the learning of foreign languages and cultures, promote study abroad, encourage students from other countries to study in the U.S., facilitate the exchange of scholars and citizens, and encourage educational infrastructure that supports international research and competence. ${ }^{1}$ In April 2000, President Clinton signed a memorandum to heads of executive departments and agencies calling for an international education policy, and Secretary of Education Richard Riley followed up this directive by calling for a doubling of exchange opportunities in U.S. higher education in the next ten years. ${ }^{2}$

To meet this call for an increased international mobility that affords U.S. students serious, well-integrated, and high-quality academic experiences abroad, U.S. educational institutions at all levels need to develop a strategy that gives students the tools to make the most of the increasing number of international educational programs available. Linguistic competency lies at the core of this preparation.

The dominance of the U.S. in political, economic, and cultural spheres and the use of English as the lingua franca of the Internet may be making students complacent about the need to be proficient in other languages even as transnational movements intensify. For Americans, the great danger of assuming the mantle of the trendsetter in the era of globalization is that we will be lulled into a situation in which the rest of the world knows all about us, but we know nothing of the rest of the world, except as it presents itself to us as a potential market. The shadow side of our economic and political dominance could turn out to be cultural underdevelopment. Already, the unfortunate sense among Americans that learning a foreign language is at most an academic exercise without much utility in careers and mature lives sets our citizens off from most other educated peoples on the planet. And, in fact, most Americans, aside from those who sustain their non-English speaking ethnic heritage, soon forget, 
if indeed they ever knew, how to speak whatever language it was that they studied in school. Language is the key to cultural understanding. Although business can be conducted in English with the Japanese or the Russians, Americans deprive themselves of entire levels of important social interaction by their monolingualism.

At the same time that enrollments in foreign languages are not keeping pace with the needs of the 21st century, there is new demand for language instruction from those who are seeking competency in the less commonly-taught languages of Africa, Southeast Asia, and the newlyindependent states of the former Soviet Union. How colleges and universities plan to meet this demand and finance the teaching of more and more languages to smaller and smaller classes is currently an important topic of discussion on many campuses.

In response to the challenges posed by globalization, many U.S. campuses are developing their own strategic plans for the internationalization of the home campus. Efforts to internationalize include more active faculty exchange, an increase in the admission of international students, a wider and more visible ethnic mix, curricular innovations, crossnational inter-university arrangements that acknowledge and encourage further language and area study in the context of an academic discipline, better access to study, work, and volunteer opportunities abroad.

What is fundamentally at stake is whether educational institutions can successfully prepare students to live effectively and happily in an increasingly interdependent world. Here, we argue the case for the enhanced role of study abroad programs in supplementing on-campus study with firsthand experiences that have the potential to make students better citizens, as well as to broaden their horizons in ways that make both work and leisure more rewarding. In the deepest sense, we are all being challenged to globalize our consciousness without losing the specifics of individual and collective identity. Such a challenge depends on simultaneously nurturing curiosity, empathy, humility, and pride. There is no better way to do this than to have an opportunity to shift our learning community for a period of time from what is familiar to what is not. Such a shift may occur under pressure in a variety of transnational careers, but it lacks the freedom and spirit of discovery that is implicit in the radical possibilities of study abroad for students who are not subject to job pressures. 
Of course, we do not intend to view these programs and their effects through rose-colored glasses. Indeed, it is unrealistic to expect that a study abroad experience in and of itself will lead to a sophisticated understanding of the dynamics and effects of globalization. Insofar as effective study abroad experiences provide the student with cultural immersion, it is incumbent upon U.S. institutions that send students abroad to prepare them academically and linguistically for entry into another culture. This preparation begins by helping students articulate their goals for study abroad and by requiring certain basic linguistic and/or cultural preparation for the sojourn. A number of study abroad programs protect students from the inevitable discomfort of living and working in an unfamiliar setting by creating hermetic domestic enclaves. Students eager for authentic in-country experiences often complain of programs that are organized in a way that socially confines them in an artificial world quite detached from the realities of the culture and daily life of the host country. Programs must creatively strive to make the experience a challenge in fact, as well as on paper, and the students who participate must be convinced that they are far more likely to benefit if they break out of their comfortable cocoons of the familiar. The challenge here resembles the contradictory experiences of tourism-either recreating the anodyne comforts of home by never straying far from international hotels and cruise ships that provide the music, food, and language that they supposedly left behind in America, or deliberately seeking the adventure of the local and unfamiliar by embarking on voyages of discovery (and risk).

Finally, we are suggesting that Americans, especially, need as much of this immersion in a foreign reality as possible. Study abroad programs, if properly conceived and executed, are an excellent and satisfying way to achieve this result. In a time of globalization, it is ironic that Americans could easily become "the new provincials," rich and powerful, yet culturally impoverished by the illusions of national self-sufficiency. As well, in a world where poverty and resentment abound, and disparities between rich and poor are growing ever greater, it is crucial to learn as much about "the reality" of "the other" as possible. We believe that study abroad programs should deliberately pursue such goals, and thereby help Americans to live more creatively and knowledgeably in a world of borderless markets, revitalized cultural tradition, and contending visions of a beneficial human future. 
Frontiers: The Interdisciplinary Journal of Study Abroad

\section{Notes}

1 "Toward an International Education Policy for the United States," NAFSA: Association of International Educators and The Alliance for International Educational and Cultural Exchange, February 22, 2000, found at http://www.nafsa.org/content/PublicPolicy/USIntlEdPolicy/ towardInternational.html.

2 Richard Riley, "The Growing Importance of International Education," comments delivered on April 19, 2000, found at http://www. ed.gov/speeches/042000/000419.html. 